\title{
Advantages and pitfalls of radioimmune and enzyme linked immunosorbent assays of insulin antibodies
}

\author{
F. Sodoyez-Goffaux ${ }^{1}$, M. Koch ${ }^{1}$, N. Dozio ${ }^{2}$, D. Brandenburg ${ }^{3}$ and J-Cl.Sodoyez ${ }^{2}$ \\ Departments of ${ }^{1}$ Paediatrics and ${ }^{2}$ Internal Medicine, University of Liège, Belgium and \\ ${ }^{3}$ German Research Institute, University of Aachen, FRG
}

\begin{abstract}
Summary. Human sera were tested for insulin antibodies by fluid and solid phase assays. Radioimmune titres determined with 125-I Tyr A14 insulin were not correlated with those obtained using insulin coated microplates and enzyme linked immunodetection $(n=60)$. Several reasons for this lack of correlation were found. Iodine substitution on the A14 residue of insulin may significantly alter the avidity of some insulin antibodies for their ligand; hence, disclosing a heretofore unsuspected pitfall for antibody determination by radioimmunoassay. Specificity for bovine insulin was easily demonstrable in fluid phase by comparing the binding of monoiodinated bovine, porcine and human insulin. By contrast, in solid phase assay, titres obtained with microplates coated with bovine or human insulin were almost equal, regardless of the serum specificity for bovine insulin. This lack
\end{abstract}

of specificity of the solid phase assay is not due to denaturation or unavailability of the bovine specific epitope because: bovine specificity could be demonstrated by competitive assay, after preincubation of the serum with insulin of the different species; and, coating with crosslinked insulin dimers or oligomers instead of monomers did not unmask bovine specificity. It is concluded that radioimmune methods are best suited to study specificity but may be biased by the presence of the radioiodine label whereas solid phase assay detects low avidity antibodies with great efficiency but is less appropriate to study specificity.

Key words: Radioimmune assay, enzyme linked immunosorbent assay, insulin antibodies.
The immune response to exogenous insulin was first reported by Banting et al. in 1938 [1] and fully described by Berson and Yalow [2]. Since their pioneering work, using 131-I-radioiodinated insulin and electrophoretic separation of free and bound hormones, various technical refinements have been developed regarding the purity and specific activity of the tracer or the method employed to separate free from antibodybound hormone [3-9].

Recently, the technique of enzyme linked immunoassay first introduced by Engvall and Perlmann [10] was applied to insulin antibody determination. In this assay, the ligand is immobilised on a solid phase, usually microplates, and bound antibodies are detected by a human immunoglobulin antibody conjugated to an enzyme. As a final step, the enzyme activity bound to the immune complexes is measured after addition of appropriate substrate [11, 12].

Detection of insulin antibodies is useful in insulin treated diabetic patients and is the mainstay of diagnosis of autoimmune hypoglycaemic syndrome [13-15]. More recently, circulating insulin antibodies have also been reported in Type 1 (insulin-dependent) diabetic patients before any administration of exoge- nous insulin [16-20]; and their diagnostic and prognostic value with regard to ongoing, yet asymptomatic, destruction of pancreatic B cells is open to debate.

At the present time, it clearly appears that currently used methods in different laboratories yield different results of insulin antibodies for the same plasma sample. This is one of the most disturbing conclusions reached after analysis of the data produced by the recent workshop on insulin antibodies [21]. Results are usually expressed in the unit system of the end signal, i. e. percent binding for radioimmunoassay or optical density for enzyme linked immunosorbent assay and it is generally assumed that antibody concentration is directly proportional to signal intensity. Tentative quantitation of insulin antibodies by Scatchard analysis or the like is not only cumbersome but also frequently impossible because of heterogeneity of insulin antibodies in insulin-treated diabetic patients.

We are therefore faced with two fundamental questions:

1. Is one of the 2 assays, performed in solid or liquid phase, better than the other with regard to sensitivity, specificity and precision? 
2. In the presence of different insulin antibodies are the performances of the 2 assays identical or are there pitfalls?

\section{Materials and methods}

\section{Insulin, proinsulin and derivatives}

Bovine, semisynthetic human, porcine, 127-I Tyr A14 and 127-I Tyr A19 monoiodinated porcine insulins were generously provided by Drs K.Jørgensen and I.Jensen, Novo Research Institute, Copenhagen, Denmark. The three species of insulin, bovine, porcine and human, were iodinated with carrier-free $\mathrm{Na} 125-\mathrm{I}$ and the isomers monoiodinated on Tyr A14 were purified by reverse phase HPLC $[22,23]$. Specific activity was $300 \mathrm{mCi} / \mathrm{mg}$. Human proinsulin and des 31,32 human proinsulin were a generous gift of Dr. B. Frank, Eli Lilly Research Laboratories, Indianapolis, Ind, USA. Des-Ala-B30porcine insulin was prepared by Dr. H.G. Gattner [24]. Human B [23-30] octapeptide was prepared by B. Vogt and F. Wedekind (German Research Institute, Aachen, FRG).

Insulin dimers and oligomers were also used as coating material. It was indeed speculated that if all insulin molecules were coated in the same manner, some epitopes would systematically be hidden or distorted. Substitution of insulin monomers by a repetitive antigen with various crosslinking bridges would hopefully cope with this potential bias. Insulin dimers and oligomers were prepared as previously described [25]. Briefly, crystalline porcine or bovine insulin was reacted with bis-(4-nitrophenyl) suberate. Gel filtration of the crude reaction product on Sephadex G50 fine in $10 \%$ acetic acid (column $5 \times 150 \mathrm{~cm}$ ) gave $30 \%$ fraction 1 (oligomers), 15\% fraction 2 (dimers) and $45 \%$ fraction 3 (monomers). The oligomeric fraction contained mainly trimers. According to the known reactivities of the insulin amino groups with this reagent $(\mathrm{A} 1>\mathrm{B} 29 \gg \mathrm{B} 1)$ and the results of disulfide cleavage by oxidative sulphitolysis, gel filtration and electrophoretic analysis of the resulting chains, dimers were mainly bridged between A1 and B29. In the oligomer fraction, crosslinking had also mainly occurred between the A1 and B29 groups of different molecules, resulting in the formation of $A-B$, and only minor amounts of $\mathrm{A}-\mathrm{A}, \mathrm{B}-\mathrm{B}$ and $\mathrm{A}-\mathrm{B}-\mathrm{A}$.

\section{Anti-insulin sera}

Over sixty human sera from unselected insulin-treated diabetic patients immunised against therapeutic insulin were collected from various sources: Paediatric and Adult Diabetes Clinics (University of Liège, Belgium), Scientific Institute San Raffaele (University of Milan, Italy), E.P.Joslin Diabetes Center (Boston, Massachusetts, USA), Department of Medicine, University of New Mexico (Albuquerque, New Mexico, USA) and Novo Research Institute (Copenhagen, Denmark). One serum originated from a non-diabetic, noninsulin-treated patient suffering from severe hypoglycaemic episodes. Her clinical course has recently been reported [26].

\section{Enzyme-linked immunosorbent assay (ELISA)}

ELISA of insulin IgG (AI-IgG) was performed as previously described [27]. Briefly, microplates were coated with $1 \mu \mathrm{g} / 75 \mu 1$ solution of insulin monomers, dimers or oligomers or with an equimolar solution of insulin derivative. Fifty $\mu \mathrm{l}$ of patients sera previously diluted $1 / 5$ were tested in serial 2 -fold dilutions $(1 / 5$ to $1 / 5,120)$. One well per row received buffer instead of serum and served as blank. Buffer contained NaH2PO4.2H2O, $5.2 \mathrm{~g}, \mathrm{~K} 2 \mathrm{HPO} 43 \mathrm{H} 2 \mathrm{O}, 36.7 \mathrm{~g}$, $\mathrm{NaCl}, 87.6 \mathrm{~g}$, Tween 20 (Merck, Darmstadt, FRG) $5 \mathrm{ml}$, bovine serum albumin (BSA, fraction V, Sigma Chemical, St Louis, Mo,
USA) $20 \mathrm{~g}$ and $\mathrm{H} 2 \mathrm{O}$ ad $101 ; \mathrm{pH}$ was adjusted to 7.2 . After $2 \mathrm{~h}$ incubation at $37^{\circ} \mathrm{C}$ and 3 successive washes, all the wells received a mouse monoclonal anti-human $\operatorname{IgG}$. After a second $2 \mathrm{~h}$ incubation at $37^{\circ} \mathrm{C}$ followed by removal of unbound mouse monoclonal antibody, the immune complexes were allowed to react with a rabbit anti-mouse Ig serum conjugated to peroxidase. After $1 \mathrm{~h}$ incubation followed by 4 washes with tap water, 2.2'-azino-di-3-ethylbenzthiazolinosulfonat 6 (ABTS, Boehringer, Mannheim, FRG) was added and oxidised chromogen was measured by reading absorbance at $405 \mathrm{~nm}$. Control sera always were below $0.2 \mathrm{U}$ optical density.

\section{Radioimmune titration (RIT)}

RIT was performed by mixing a constant amount of 125-I Tyr A14 insulin, $(20,000 \mathrm{cpm} / 100 \mathrm{ul})$ with duplicate $100 \mathrm{ul}$ samples of serial 2 -fold serum dilutions. Sera were diluted with phosphate buffered saline (PBS) (sodium phosphate: $0.015 \mathrm{~mol} / \mathrm{l}, \mathrm{NaCl}: 0.15 \mathrm{~mol} / 1$ and bovine serum albumin: $0.35 \%, \mathrm{pH} 7.4)$. After overnight incubation at $4^{\circ} \mathrm{C}, 0.4 \mathrm{ml}$ of dextran-coated charcoal (1 volume of charcoal suspension, $50 \mathrm{mg} / \mathrm{ml}$ PBS and 1 volume of Dextran $770,5 \mathrm{mg} / \mathrm{ml}$ PBS) and $1 \mathrm{ml}$ of ice-cold PBS were added and the suspension thoroughly mixed. Ten min later, the tubes were spun at $2300 \mathrm{~g}$ for $10 \mathrm{~min}$ in a refrigerated centrifuge, precipitates and supernatants were separated and their activity counted. Antibody bound hormone was estimated by calculating the percentage of activity in the supernatant. Blank values obtained by substituting buffer for serum ranged from 2 to $4 \%$ and were not subtracted from sample values. Control sera always were below $6 \%$ at the $1 / 5$ dilution.

\section{Competitive inhibition of binding}

Insulin dilutions to be used as competitors were made from spectrophotometrically calibrated stock solutions in $0.01 \mathrm{~N} \mathrm{HCl}$. Molar extinction coefficients (E) at $276 \mathrm{~nm}$ were $5.59 \cdot 10^{3} \mathrm{~mol}^{-1} \mathrm{~cm}^{-1}$ for insulin and proinsulin and $6.31 \cdot 10^{3} \mathrm{~mol}^{-1} \mathrm{~cm}^{-1}$ for monoiodinated insulin [28].

One hundred $\mu \mathrm{l}$ of $125-\mathrm{I}$ insulin of the different species, $100 \mu \mathrm{l}$ of buffer or competitor solution at increasing concentrations and $100 \mu \mathrm{l}$ of appropriate serum dilution were incubated overnight at $4^{\circ} \mathrm{C}$. Bound and free hormones were separated as described above.

\section{Statistical analysis}

Correlation between 2 parameters were calculated using standard least squares method.

\section{Results}

\section{Correlation between titres determined in liquid and solid phase}

Serial dilutions of 60 human sera containing insulin antibodies were tested by ELISA using bovine insulin coated plates and a titre corresponding to $0.8 \mathrm{U}$ of optical density was derived. Serial dilutions of the same sera were incubated with a constant amount $( \pm 20,000 \mathrm{cpm})$ of 125 -I labelled bovine insulin and a titre corresponding to tracer binding of $40 \%$ was similarly derived. In some instances, when apparent level of anti-insulin antibodies was low, titres were 

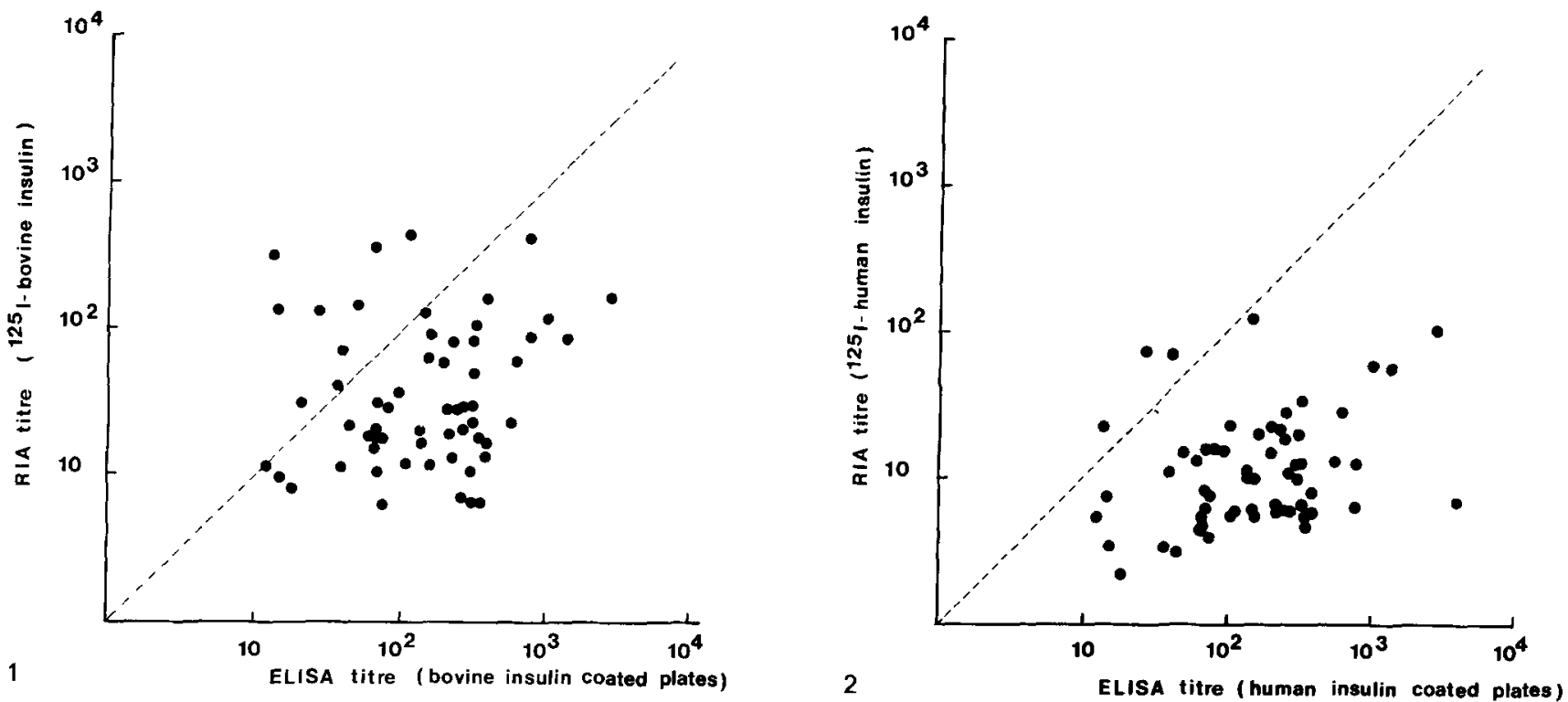

Fig. 1. Correlation between RIA (y) and ELISA (x) titres obtained with bovine ligand. The dashed line is the line of equality. Log $y=0.137$ $\log \mathrm{x}+1.248(n=59) ; r^{2}=0.022 ;(p>0.05)$. The serum of a patient with autoimmune hypoglycaemic syndrome was negative in the presence of bovine ligand in both assays

Fig. 2. Correlation between RIA (y) and ELISA $(x)$ titres obtained with human ligand. The dashed line is the line of equality. Log $y=0.199$ $\log \mathrm{x}+0.609(n=60) ; r^{2}=0.082 ;(p>0.05)$
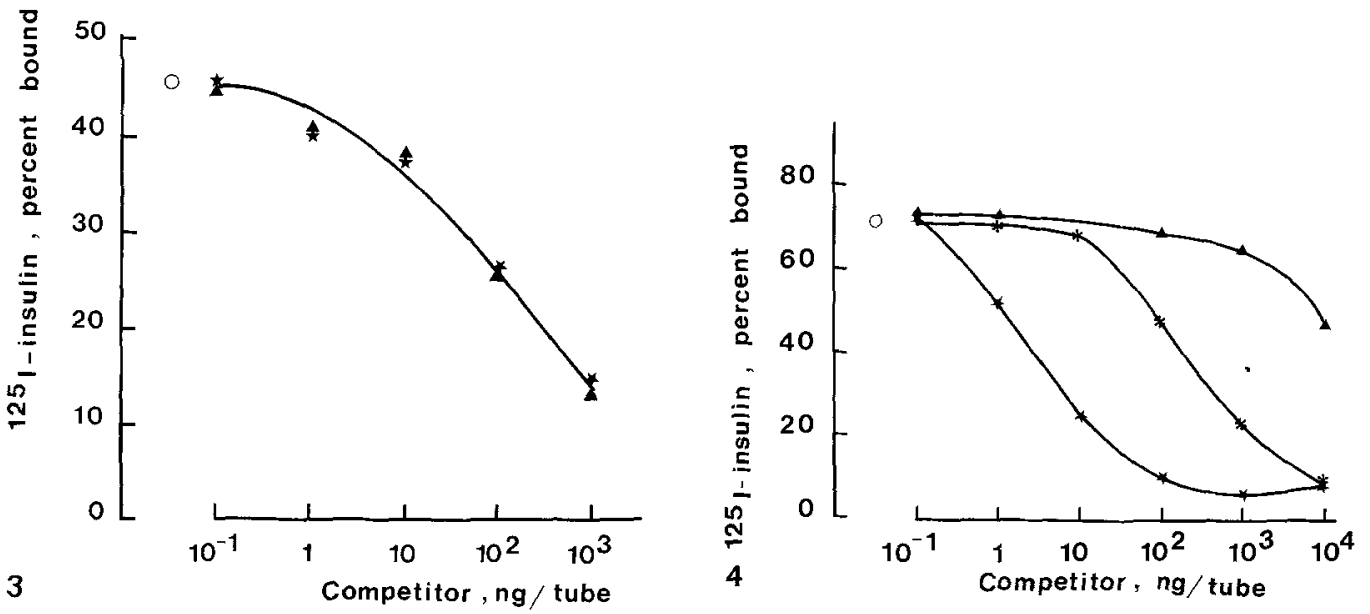

Fig.3. Competitive inhibition of binding of 125-I Tyr A14 human insulin with native ( $\wedge$ ) or 127-I Tyr A14 monoidinated porcine insulin ( $\star$ ). The open circle $(O)$ corresponds to tracer binding in the absence of competitor. For most sera, as for the one illustrated in this figure, iodine substitution on A14 exerted no influence on antibody interaction

Fig.4. Competitive inhibition of binding of 125-I Tyr A14 porcine insulin with native (A), 127-I Tyr A14 ( $\star$ ) or 127-I Tyr A19 (**) monoiodinated porcine insulin. The open circle $(O)$ corresponds to tracer binding in the absence of competitor. This figure illustrates A14 iodine enhancement of insulin antibody interaction

calculated for an optical density of $0.4 \mathrm{U}$ and tracer binding of $20 \%$. As shown by Figure 1 , there was no correlation $\left(r^{2}=0.02\right)$ between titres determined in solid ( $\mathrm{x}$ axis) and liquid (y axis) phase. Closer examination of Figure 1 shows that 8 out of 60 sera had greater RIA than ELISA titres. The same 60 sera were compared using human ligand, i.e. human insulin coated plates and 125-I labelled human insulin (Fig.2). Once again, no correlation was found $\left(r^{2}=0.08\right)$ but only 3 out of the 60 sera had greater RIA than ELISA titres.

\section{Effect of iodine substitution on Tyr A14}

The relative potencies of native and 127-I Tyr A14 porcine insulin to compete for 125-I porcine insulin binding were compared in fluid phase assay. Because of the scarcity of the purified 127-I Tyr A14 insulin, only 17 sera could be tested. For 10 of them, the 2 competitors were equipotent (Fig. 3). Seven sera displayed a higher avidity for the monoiodinated than for the native ligand. The difference of potency was usually low, less than 10 . In 2 instances, it was higher than 10,000-fold (Fig.4). 


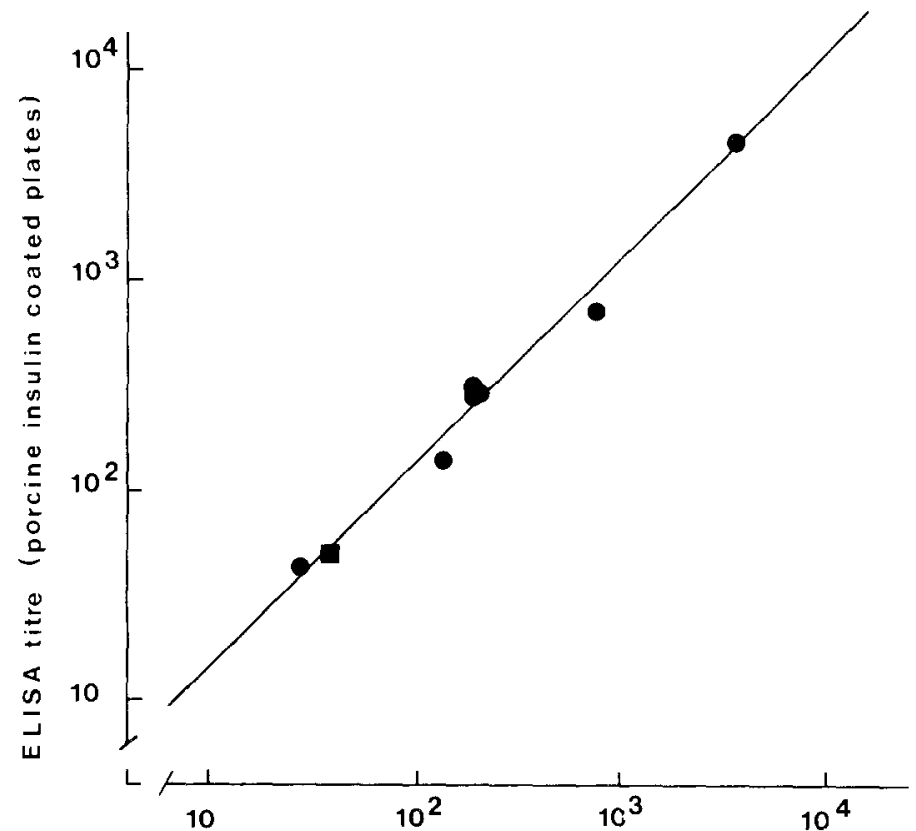

5

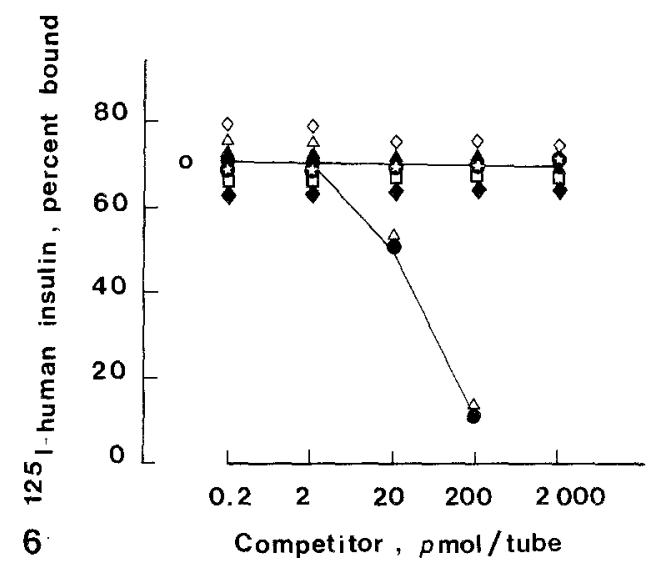

Fig.5. Correlation between ELISA titres obtained with plates coated with native insulin (y) or 127-I Tyr A14 monoiodinated insulin (x). The serum illustrated in Figure 4 ( $)$ was compared with seven sera which, in liquid phase, equally bound native insulin and its A14 monoiodinated derivative (0). $\left.\log y=0.98 \log \mathrm{x}+0.19(n=8) ; r^{2}=0.989 ; p<0.001\right)$

Fig. 6. Competitive binding assay of the serum of a patient with autoimmune hypoglycaemic syndrome. 125-I Tyr A14 human insulin binding was measured in the absence $(O)$ or in the presence of increasing concentrations of competitors: human insulin, $\Delta$ porcine insulin, threonine, Thuman B23-30 octapeptide, $\square$ human proinsulin, $\triangle$ des 31,32 human proinsulin and $\diamond$ des B30 porcine insulin

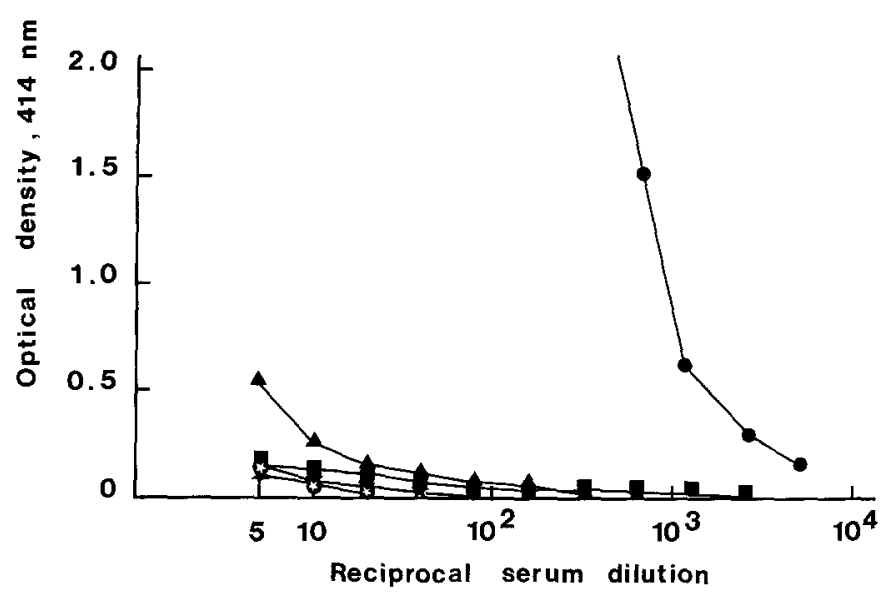

Fig.7. ELISA titration of the same autoimmune serum as in Figure 6 using microplates coated with human $(\boldsymbol{O})$, porcine $(\boldsymbol{\Lambda})$ or bovine ( $\mathbf{(})$ insulins, des B30 porcine insulin $(\boldsymbol{A})$ or human proinsulin (*)

ELISA titres of 7 sera which, in liquid phase, equally bound native and 127 I Tyr A14 insulin, were determined using microplates coated with native or 127-I Tyr A14 porcine insulin. As shown by Figure 5, titres obtained with the monoiodinated hormone were slightly lower but well correlated $(p<0.001)$ with those obtained with the native hormone. The serum which, in liquid phase, displayed the most remarkable increase of avidity for insulin monoiodinated in position A14 was similarly tested and did not exhibit any pref- erence for binding iodinated insulin in solid phase assay (Fig. 5).

\section{Effect of specificity for human insulin}

One autoimmune serum was highly specific for human insulin. Indeed, in the radioimmune system, it bound human but not porcine or bovine 125-I labelled tracers (data not shown). In competitive assay, human 125-I insulin binding was inhibited by unlabelled human insulin and des 31,32 human proinsulin (i.e. proinsulin without residues 31,32 ) but not by human proinsulin, bovine or porcine insulin, des B30 porcine insulin, B (23-30) human insulin octapeptide or free threonine (Fig.6). High specificity for human insulin was also exhibited in ELISA. Indeed, insulin antibodies were bound to human but not to bovine or porcine insulin coated plates (Fig. 7).

\section{Effect of specificity for bovine insulin}

Twelve sera were selected because they displayed specificity for bovine insulin in liquid phase assay. As shown by Figure 8 (left panel), the ratio of radioimmune titres determined with bovine and human tracers ranged from 3 to 65 . When the same sera were assayed in solid phase, using human or bovine insulin coated 

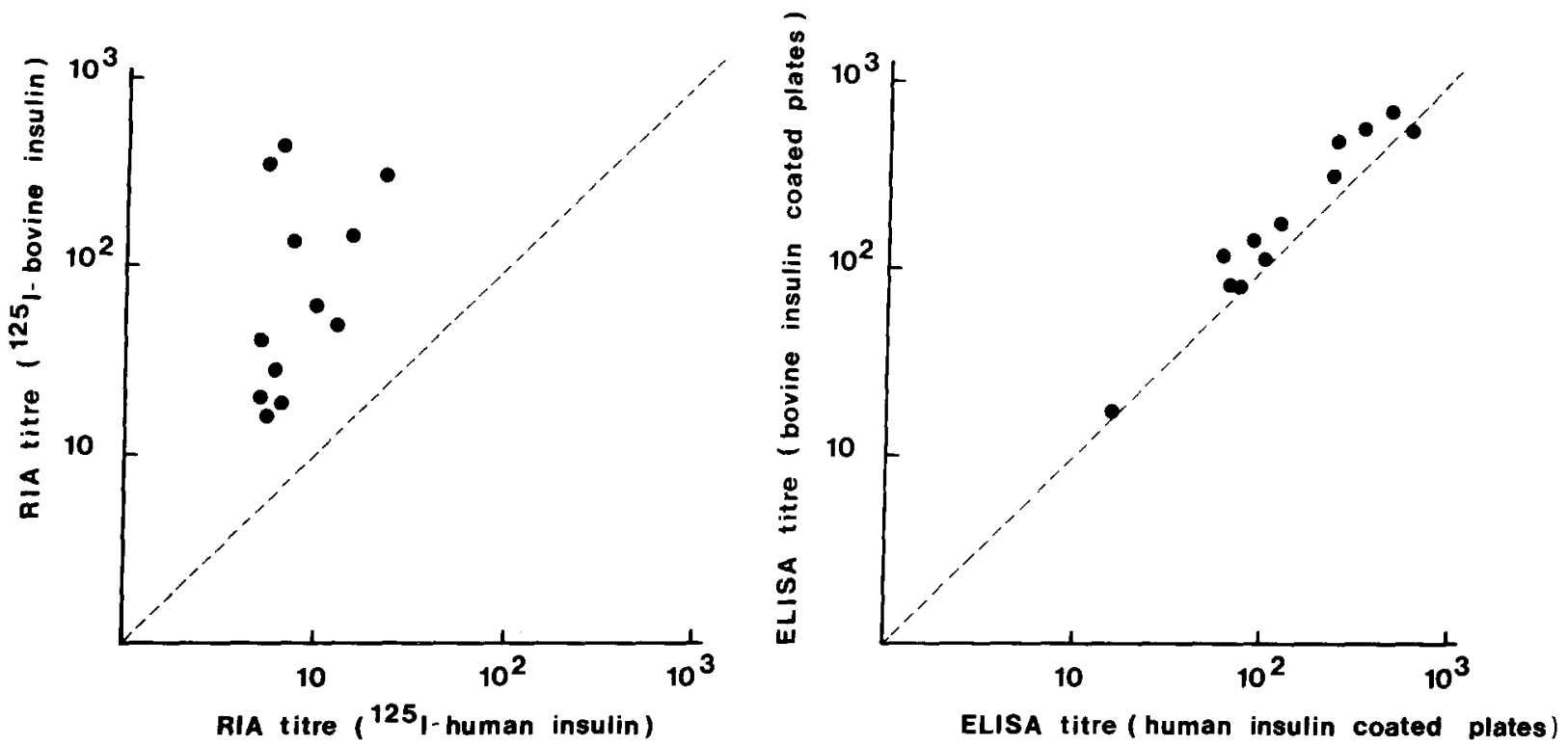

Fig. 8. Correlation between titres of 12 bovine specific sera determined in fluid (left) or solid (right) phase assays. The ligands were bovine insulin (y) or human insulin (x). The dashed lines are the lines of equality. Log $\mathrm{y}=0.979 \log \mathrm{x}+0.983 ; r^{2}=0.185 ; p>0.05$ for fluid phase assay and $\log \mathrm{y}=1.039 \log \mathrm{x}+0.045 ; r^{2}=0.95 ; p<0.001$ for solid phase assay

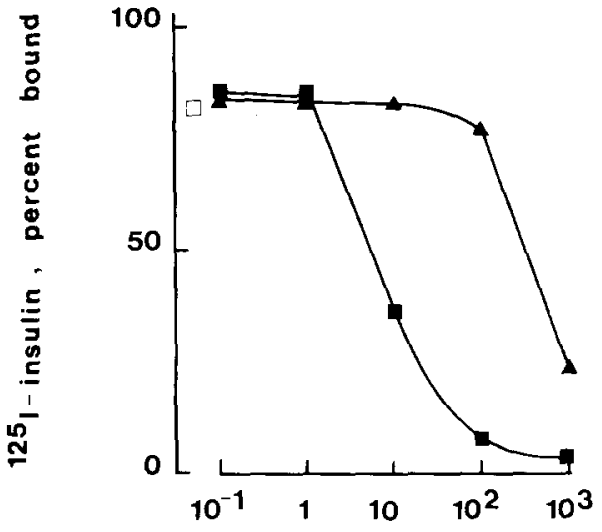

9
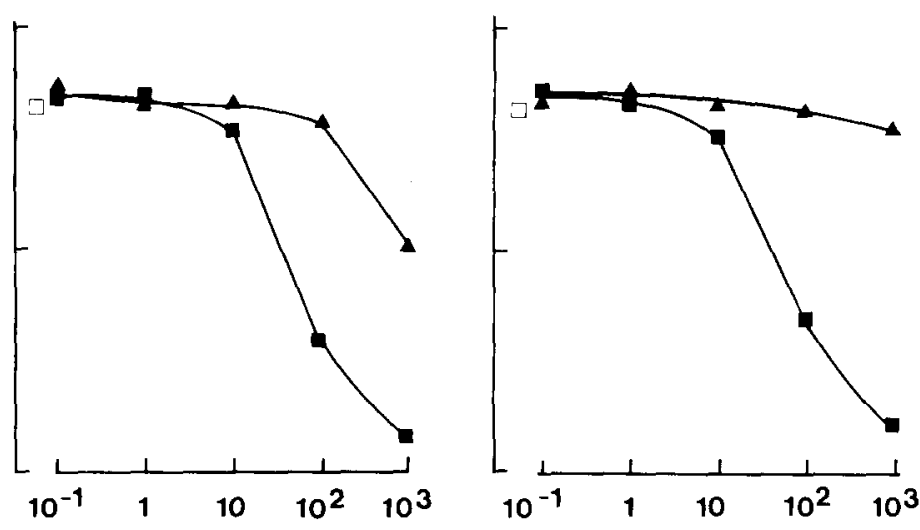

Competitor, ng/tube

Fig.9. Competitive binding assay of a highly bovine specific insulin antiserum in liquid phase. The serum was incubated with bovine 125-I Tyr A14 insulin alone ( $(\square)$ or mixed with increasing concentrations of competitors of bovine ( $\mathbf{C})$ or porcine (A) origin. Competitors were insulin monomers (left panel), dimers (middle panel) or oligomers (right panel)

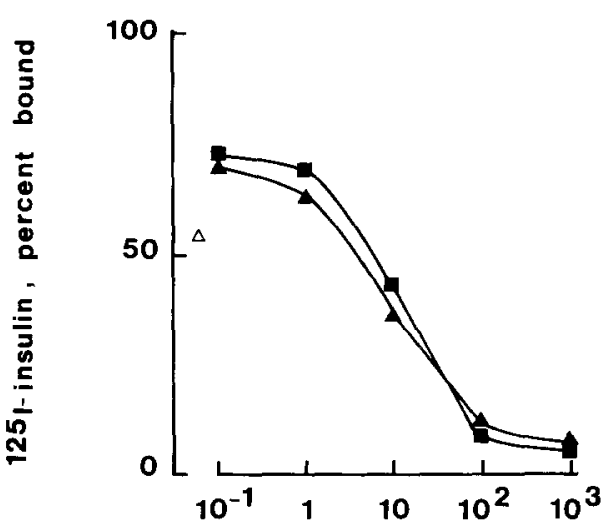

10
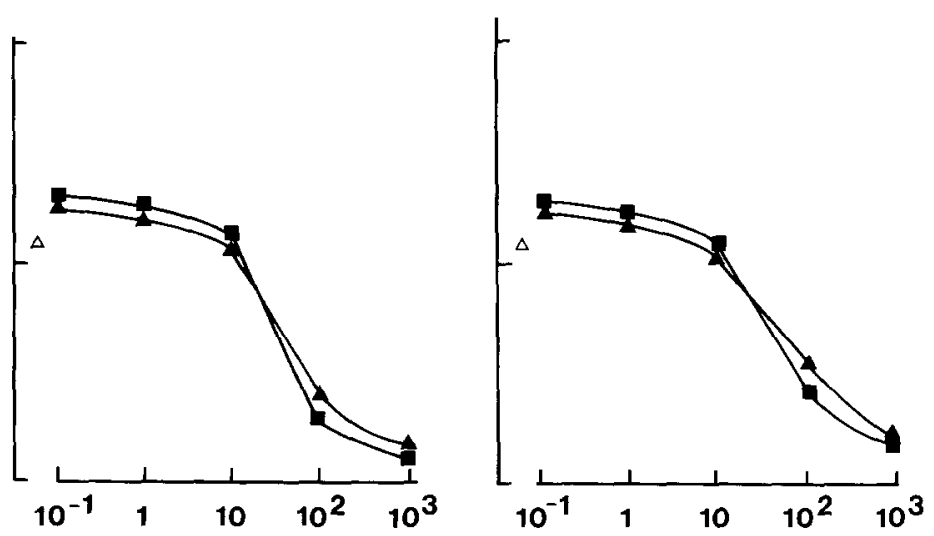

Competitor, ng/tube

Fig. 10. Competitive binding assay of a highly bovine specific insulin antiserum in liquid phase. The serum was incubated with porcine 125-I Tyr A14 insulin alone $(\Delta)$ or mixed with increasing concentrations of competitors of bovine $(\boldsymbol{\square})$ or porcine (A) origin. Competitors were insulin monomers (left panel), dimers (middle panel) or oligomers (right panel) 
plates, species specificity could no longer be demonstrated (Fig. 8, right panel). Titres obtained with plates coated with bovine insulin were slightly higher than

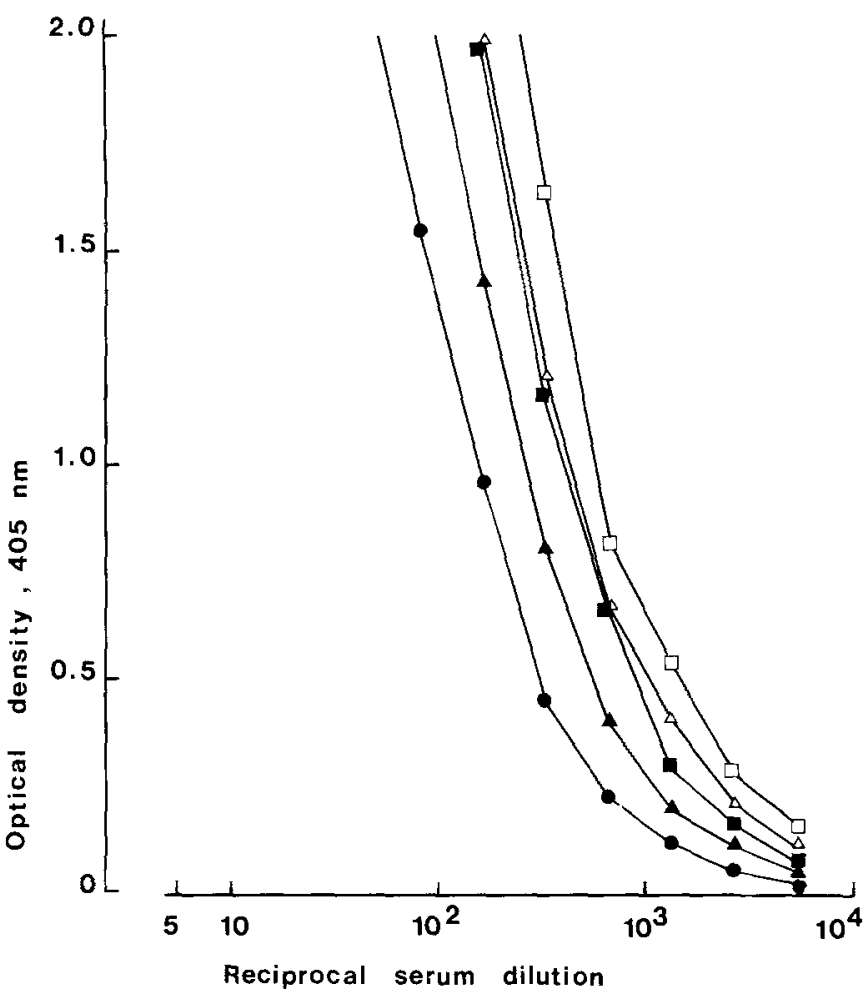

Fig. 11. ELISA of the same highly bovine specific insulin serum as in Figures 9 and 10. Plates were coated with monomers of human insulin $(\boldsymbol{O})$, dimers of bovine $(\boldsymbol{\square})$ or porcine $(\boldsymbol{\Lambda})$ insulin or with oligomers of bovine $(\square)$ or porcine $(\Delta)$ insulin those obtained with human insulin, but for none of the assayed serum did the ratio between the 2 titres ever exceed 2 . Furthermore, a highly statistically significant $\left(r^{2}=0.95 ; p<0.001\right)$ correlation existed between the 2 sets of ELISA titres.

\section{Effect of insulin conjugates}

The serum with the highest specificity for bovine insulin was selected for further studies using crosslinked insulin conjugates. As shown by Figure 9 (left panel), in liquid phase assay, unlabelled bovine insulin was a 60-fold better competitor for bovine tracer than unlabelled porcine insulin. In the presence of porcine tracer (Fig.10, left panel), bovine and porcine insulins were almost equipotent competitors. Insulin dimers and oligomers were slightly less potent than the corresponding monomers. However, species specificity remained clearly demonstrable irrespective of the degree of insulin polymerisation (Fig. 9 and 10, middle and right panels).

Using plates coated with bovine or porcine insulin dimers, the same highly bovine specific serum as in Figures 9 and 10 repeatedly yielded titration curves which at the most differed by a factor of 2 , i.e. one serum dilution. Similar results were obtained in the presence of coated bovine or porcine insulin oligomers (Fig. 11). In solid phase, species specificity could only be demonstrated in competitive assay. Using bovine insulin coated plates and serum preincubation with

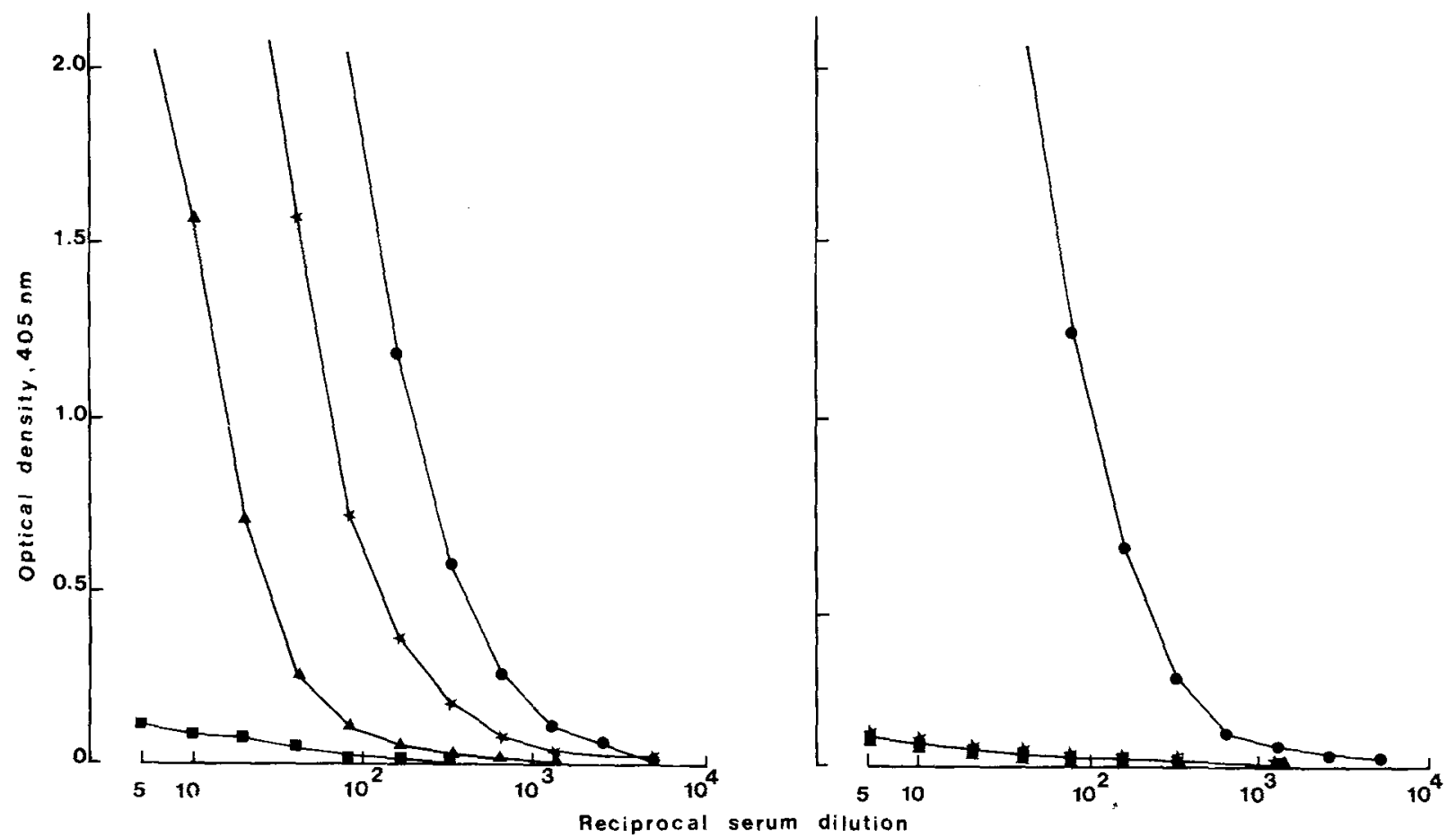

Fig. 12. ELISA of the same highly bovine specific insulin serum as in Figures 9-11. The serum was employed without prior incubation ( $)$ or was preincubated with $200 \mu \mathrm{g} / \mathrm{ml}$ human insulin (*), bovine insulin (ם) or porcine insulin (A). Microplates were coated with bovine (left panel) or human (right panel) insulin 
equimolar amounts of the different competitors, it clearly appears that the inhibiting potency decreased from bovine to porcine and human insulin (Fig. 12, left panel). On the contrary, employing human insulin coated plates, the same amount of the 3 insulins completely inhibited insulin antibody binding to the plate (Fig. 12, right panel).

\section{Discussion}

Radioimmune- and enzyme-linked-immunosorbent assays of insulin antibodies are both based on insulin interaction with specific antibodies. Yet, surprisingly, results obtained with both methods were not correlated.

In an attempt to account for discrepancies between the two assays, we successively examined potential differences between them. Of course, RIA detects all antiinsulin immunoglobulins whereas, depending upon the choice of immune reagent, ELISA is restricted to one class or subclass of anti-insulin antibodies. In general, however, anti-insulin antibodies belong to the IgG class and, provided that anti-human $\operatorname{IgG}$ is used in ELISA, both assays should yield comparable results.

Native insulin is used in ELISA and 125-I Tyr A14 insulin in RIA. Monoiodination of insulin is known to alter sensitivity to "insulinase" [28]. Furthermore, as more recently demonstrated, receptor affinity and biological potency are modified according to iodine position $[29,30]$. If monoiodination may modify insulin interaction with its receptors, it might likewise affect insulin interaction with other proteins, particularly with insulin antibodies. Among the sera examined by RIA, several displayed a higher avidity for 127 I-Tyr A14 insulin than for the native hormone and the increase of avidity was as high as 10,000 -fold for one serum. This suggests that residue A14 is sometimes included in an antigenic determinant and that monoiodination of this tyrosine residue, in some cases, improves the fit between the epitope and the paratope.

In other instances, one may speculate that iodination rather impairs the antigen-antibody fit. A similar reasoning may probably be applied to monoiodination of the other tyrosyl residues of insulin, so that, there is little doubt that iodination of insulin may, sometimes to a great extent, bias determination of insulin antibodies by radioimmunoassay. Erroneous estimation of insulin antibody level may have clinical implications. Tremendous (more than 1000-fold) amplification of antibody binding by A14 monoiodination occurred in 2 of our patients. One developed these peculiar antibodies after switching from conventional therapy to continuous subcutaneous pump infusion of human insulin. Apparent hyperimmunisation against insulin motivated cessation of pump treatment and return to conventional therapy. The other patient was treated by 2 daily subcutaneous injections of purified porcine in- sulin. As her insulin requirement was higher than $100 \mathrm{U}$ per day and her level of insulin antibody was misdiagnosed as extremely high, she was considered as resistant, her resistance was attributed to immunisation against insulin and immunosuppressive therapy was contemplated but fortunately not initiated after correct characterisation of her antibodies.

In solid phase assay, iodine substitution of Tyr A14 had no significant effect, even in the presence of the serum containing antibodies which, in liquid phase, demonstrated an exquisite sensitivity to insulin monoiodination.

The human specific insulin antibodies described in this study are likely directed against one single epitope. For antibody binding, threonine B30 must be not only present but also free. Indeed, these antibodies do not bind bovine or porcine insulins in which threonine B30 is replaced by alanine. Removal of threonine B30 (as in des B30 porcine insulin) or its engagement in a peptide bond (as in human proinsulin) completely abolished antibody binding. In addition, these antibodies do not bind threonine itself nor the carboxy terminal octapeptide of the human B chain. It is therefore postulated that they are directed against a single conformational epitope which contains B30 and extends to nearby aminoacids of the B chain but possibly also of the amino terminal extremity of the A chain. These anti-insulin immunoglobulins belong to one single subclass of $\operatorname{IgG}$ (IgG3) and are made with only one type of light chain, suggesting that they are not only monoidiotypic but also "monoclonal (-like)" autoimmune antibodies. Clearly, as shown by Figure 7, in coated insulin molecules, the conformation of the B30 containing epitope is unaltered. This epitope is exposed to the solvent and readily accessible for antibody binding.

In solid phase, using direct anti-insulin IgG binding, bovine specificity cannot unambiguously be demonstrated, even for sera which, in liquid phase, display over 50 -fold greater avidity for bovine than for human radiolabelled insulin. A possible explanation is that the bovine specific epitope is no longer available for antibody binding because it is part of the coating surface or because, as already documented for other proteins [31], its conformation is altered in coated molecules. This implies that insulin adsorption does not occur at random but rather in an ordinate manner. Depending upon the interactive forces between insulin and polystyrene, the same surfaces of all insulin molecules would be either "hidden" or "denatured" or "exposed to the solvent".

Two lines of evidence indicate that the bovine specific epitope is not hidden or distorted. Firstly, in agreement with Nell and coworkers [11], specificity for bovine insulin can be detected in solid phase by competitive binding assay. Secondly, to unmask "hidden" epitopes or to prevent conformational alteration of some epitopes, insulin should be pushed out by a 
spacer molecule into the liquid phase. A similar approach has recently been used to improve an immunocapture assay in which monoclonal antibodies were linked to a carrier protein. This permitted antibodies to complex with the antigen at some distance from the plastic surface and increased 5 to 400 -fold the binding capacity compared to that of antibodies directly adsorbed on plastic [32]. To avoid non-specific interference with the spacer molecule, insulin itself served as "spacer" and suberoyl crosslinked insulin dimers and oligomers were used. In liquid phase, we verified that these covalent conjugates retain the properties of species specificity ( Fig.9 and 10). In solid phase, when these same conjugates were used as coated material, species specificity could not be demonstrated despite the reasonable assumption that statistically, all the epitopes of the monomer are exposed at least once at the surface of these polymorphous polymers.

Thus, instead of assuming that bovine specific antibodies are not detected in ELISA, we must consider the alternative hypothesis that they are almost equally detected with human and bovine insulin coated plates. In other words, ELISA would be much less sensitive than RIA to the affinity of the antigen-antibody interaction, a hypothesis which is supported by the following considerations on amount and spatial distribution of ligand. Indeed, in fluid phase assay, $0.06 \mathrm{ng} 125-\mathrm{I}$ Tyr A14 insulin are dispersed in a volume of $200 \mu \mathrm{l}$. In solid phase assay, we estimated that $140 \mathrm{ng}$ insulin (i.e. 2000 -fold more than in RIA) were coated on each well, resulting in an extremely high concentration of ligand in the virtual fluid layer adjacent to the well wall [26]. Thus, although the law of mass action is not applicable in a straightforward manner, it is easy to understand that the tremendously high insulin concentration achieved at the water polystyrene interface will strongly favor binding of antibodies, even of low avidity. It is interesting to note than when our most bovine specific serum was submitted to affinity chromatography, bovine specific antibodies were retained by the human insulin-sepharose-column almost as well as by the bovine insulin-sepharose one. Thus, also in this system, species specificity was not demonstrable, probably because the ligand was also in excess.

The same reasoning could probably explain that insulin iodination may have an effect on antibody binding in liquid and not in solid phase assay.

In conclusion, ELISA seems to be less sensitive than RIA to the avidity of the antigen-antibody interaction. As an advantageous consequence, ELISA would detect with greater efficiency insulin antibodies which display a low avidity for insulin, a property commonly found in insulin autoantibodies. Actually, it is not exceptional that insulin autoantibodies are detectable by ELISA only and fully escape detection by the most sensitive RIA method. In addition, as it is a "capacity" assay, ELISA could probably be standardised by means of a reference serum or pool of sera. As a disadvantageous consequence, ELISA does not allow detection of small differences between closely related structures such as the bovine or porcine and human A chain loops. By contrast, RIA is better suited to study high avidity antibodies and their specificity. It should, however, be kept in mind that, in some instances, iodination of the ligand may alter its interaction with specific antibodies. Finally, an interesting characteristic of ELISA is its versatility. Indeed, by selecting appropriate immune reagents, insulin antibodies can not only be detected but also characterised with regard to their heavy or light chains [27].

Acknowledgments. This work was supported by grants from the Fonds de la Recherche Scientifique Médicale, the National Lottery (Brussels, Belgium) Novo Industry AS (Copenhagen, Denmark), and the SFB113 Diabetesforschung (Düsseldorf, FRG). N. Dozio was in part supported by The Scientific Institute San Raffaele (Milano, Italy). The authors wish to thank Ms. Ch. François-Gerard for helpful discussion, Ms. C. Formen for excellent technical assistance, Ms. C.J.De Vos for careful preparation of the illustrations and Ms. Hoste-Fodor for excellent secretarial assistance.

\section{References}

1. Banting FG, Franks WR, Gairns S (1938) Physiological studies in metrazole shock. VII. Anti-insulin activity of insulin treated patients. Am J Psychol 95: 562-564

2. Berson SA, Yalow RS (1959) Quantitative aspects of the reaction between insulin and insulin-binding antibody. $\mathrm{J}$ Clin Invest 38: 1996-2016

3. Christiansen AH (1970) A new method for determination of insulin-binding immuno-globulins in insulin-treated diabetic patients. Horm Metab Res 2: 187-188

4. Jorgensen KH, Larsen UD (1980) Homogeneous mono- ${ }^{125}$ I-insulins: preparation and characterisation of mono- ${ }^{125} \mathrm{I}$-(Tyr A14)and mono- ${ }^{125}$ I-(Tyr A19)-insulin. Diabetologia 19: 546-554

5. Herbert V, Lau KS, Gottlieb CW, Bleicher SJ (1965) Coated charcoal immunoassay of insulin. J Clin Endocrinol Metab 25: $1375-1384$

6. Dixon K (1974) Measurement of antibodies to insulin in serum. Clin Chem 20: 1275-1281

7. Reeves WG, Kelly U (1980) An immunochemical method for the quantitation of insulin antibodies. J Immunol Methods 34: 329-338

8. Desbuquois B, Aurbach GB (1971) Use of polyethylene glycol to separate free and antibody-bound peptide hormones in radioimmunoassays. J Clin Endocrinol Metab 33: 732-738

9. Kurtz AB, Nabarro JDN (1980) Circulating insulin-binding antibodies. Diabetologia 19: 329-334

10. Engvall E, Perlmann P (1972) Enzyme-linked immunosorbent assay, ELISA. III. Quantitation of specific antibodies by enzymelabeled anti-immunoglobulin in antigen coated tubes. J Immunol 109: 129-135

11. Nell LJ, Virta VJ, Thomas JW (1985) Application of a rapid enzyme-linked immunosorbent microassay (ELISA) to study human anti-insulin antibody. Diabetes 34:60-66

12. Wilkin T, Nicholson S; Casey C (1985) A micro enzyme-linked immunosorbent assay for insulin antibodies in serum. J Immunol Methods 76: 185-194

13. Hirata Y, Ishizu H, Ouchi N, Motomura S, Abe M, Hara Y, Wakasugi H, Takahashi I, Sakano H, Tanaka M, Kawano H, Kanesaki T (1970) Insulin autoimmunity in a case with spontaneous hypoglycemia. Jap J Diabetes 13: 312-319

14. Ichihara K, Shima K, Saito Y, Nonaka K, Tarui S, Nishikawa M 
(1977) Mechanism of hypoglycemia observed in a patient with insulin autoimmune syndrome. Diabetes 26: 500-506

15. Goldman J, Baldwin D, Rubenstein AH, Klink DD, Blackard WG, Fisher LK, Roe TF, Schnure JJ (1979) Characterization of circulating insulin and proinsulin-binding antibodies in autoimmune hypoglycemia. J Clin Invest 63: 1050-1059

16. Palmer JP, Asplin CM, Clemons $\mathrm{P}$, Lyen $\mathrm{K}$, Tatpati $\mathrm{O}$, Raghu PK, Paquette TL (1983) Insulin antibodies in insulin-dependent diabetics before insulin treatment. Science 222: 1337-1339

17. Dean BM, Becker F, McNally JM, Tarn AC, Schwartz G, Gale EAM, Bottazzo GF (1986) Insulin autoantibodies in the prediabetic period: correlation with islet cell antibodies and development of diabetes. Diabetologia 29: 339-342

18. Wilkin T, Armitage M, Casey C, Pyke DA, Hoskins PJ, Rodier M, Diaz JL, Leslie RDG (1985) Value of insulin autoantibodies as serum markers for insulin-dependent diabetes mellitus. Lancet I: 480-482

19. Arslanian SA, Becker DJ, Rabin B, Atchison R, Eberhardt M, Cavender D, Dorman J, Drash AL (1985) Correlates of insulinantibodies in newly diagnosed children with insulin-dependent diabetes prior to insulin therapy. Diabetes 34: 926-930

20. Atkinson MA, MacLaren NK, Riley WJ, Winter WE, Fisk DD, Spillar RP (1986) Are insulin autoantibodies markers for insulindependent diabetes mellitus? Diabetes 35: 894-898

21. Wilkin T, Palmer J, Bonifacio E, Diaz JL, Kruse V (1987) First international workshop on the standardisation of insulin autoantibodies. Diabetologia 30: 676-677

22. Markussen J, Larsen UD (1980) The application of HPLC to the analysis of radio-iodinated tracers of glucagon and insulin. In: Brandenburg D, Wollmer A, Gattner HG (eds) Insulin, chemistry, structure and function of insulin and related hormones. De Gruyter, Berlin, pp 161-168

23. Sodoyez JC, Sodoyez-Goffaux F, Guillaume M, Merchie G (1983) Insulin metabolism in normal rats and human: external detection by a scintillation camera. Science 219: 865-867

24. Schmitt EW (1978) Verbesserte Darstellung von Des-alanyl B30insulin. Hoppe-Seyler's Physiol Chem 359: 799-802

25. Brandenburg D (1972) Preparation of $N^{A 1}, N^{B 29}$ adipoylinsulin, an intramolecularly crosslinked derivative of beef insulin. Hoppe-Seyler's Z Physiol Chem 353: 869-873
26. Sklenar I, Wilkin TJ, Diaz JL, Erb P, Keller U (1987) Spontaneous hypoglycemia associated with autoimmunity specific to human insulin. Diabetes Care 10: 152-159

27. Koch M, François-Gerard C, Sodoyez-Goffaux F, Sodoyez JC (1986) Semi-quantitative assessment of antiinsulin total IgG and IgG subclasses in insulin-immunised patients using a highly sensitive immunochemical micromethod. Diabetologia 29: 720-726

28. Sodoyez JC, Sodoyez-Goffaux F, Goff MM, Zimmerman AE, Arquilla ER (1975) 127-I or carrier-free 125-I monoiodoinsulin. Preparation, physical, immunological and biological properties and susceptibility to "insulinase" degradation. J Biol Chem 250: $4268-4277$

29. Gliemann J, Sonne O, Linde S, Hansen B (1979) Biological potency and binding affinity of monoiodoinsulin with iodine in tyrosine A14 or tyrosine A19. Biochem Biophys Res Commun 87: $1183-1190$

30. Frank BH, Peavy DE, Hooker CS, Duckworth WC (1983) Receptor binding properties of monoiodotyrosyl insulin isomers purified by high performance liquid chromatography. Diabetes 32: 705-711

31. Killshaw Pl, McEwan FJ, Backer KC, Cant AJ (1986) Studies on the specificity of antibodies to ovalbumin in normal human serum. Technical considerations in the use of ELISA methods. Clin Exp Immunol 66: 481-489

32. Suter M, Butler JE (1986) The immunochemistry of sandwich ELISA II. A novel system prevents the denaturation of capture antibodies. Immunol Lett 13: 313-319

Received: 31 March 1988

and in revised form: 19 July 1988

Dr. J.-Cl. Sodoyez

Department of Internal Medicine

University of Liège

$\mathrm{CHU}$

Sart Tilman par

B-4000 Liège 1

Belgium 